\title{
Budget analysis for reactive plume transport over idealised urban areas
}

\author{
Zhangquan Wu and Chun-Ho Liu* ${ }^{*}$
}

\begin{abstract}
Pedestrian-level air quality in urban areas is largely affected by the pollutants emitted from street canyons to the atmospheric boundary layer (ABL). Most vehicular exhausts are chemically reactive that evolve to their secondary counterparts. Besides, building roughness modifies the flows, which, in turn, influences the chemical reactions in the $A B L$. The ABL pollutant transport is affected by advection, diffusion, and chemical reactions. The roles of individual terms and their collective effect on the overall ABL pollutant transport are not yet clear. In this study, turbulent dispersion of reactive pollutants in the ABL over hypothetical urban area in the form of an array of idealised street canyons is investigated using large-eddy simulation. Nitric oxide (NO) is emitted from the ground level of the first street canyon into the urban $\mathrm{ABL}$ doped with ozone $\left(\mathrm{O}_{3}\right)$. Budget analysis of the transport processes is conducted. It is found that the contributions from advection, diffusion, and chemistry vary in the streamwise direction and they couple closely with each other. For inert pollutants, streamwise advection and vertical diffusion mainly counterbalance each other. For chemically reactive pollutants, on the other hand, chemistry plays a key role in the far field where the mixing of pollutant species is rather uniform. In view of the elevated shear stress at the roof level, advection, diffusion, and chemistry show abrupt changes, complicating the pollutant dispersion processes.
\end{abstract}

Keywords: Nitric oxide NO transport, Large-eddy simulation (LES), Ozone $\mathrm{O}_{3}$ titration

\section{Background}

Air quality problems have aroused major public concern recently especially in urban areas with dense population. Elevated pedestrian-level pollutant concentrations are commonly found in metropolises because of the heavy traffic emission in dense built environment.

Vehicular exhaust has become one of the major pollutant sources in urban areas. Nitrogen oxides $\left(\mathrm{NO}_{x}\right)$ are some of the major pollutants in the atmospheric boundary layer (ABL) whose high concentrations would adversely affect the health of inhabitants. According to the Environmental Protection Department (EPD) of Hong Kong Special Administrative Region (HKSAR), the total $\mathrm{NO}_{x}$ emission in HKSAR in 2015 was about 91,700 tonnes. One of the major emission sources is road transport, contributing more than $18 \%$ to the total $\mathrm{NO}_{x}$ emission (EPD 2016). It is noteworthy that most vehicular

\footnotetext{
*Correspondence: liuchunho@graduate.hku.hk

Department of Mechanical Engineering, The University of Hong Kong,
}

7/F, Haking Wong Building, Pokfulam Road, Hong Kong, China exhausts are chemically reactive that evolve to their secondary counterparts in the ABL which further complicate the processes of pollutant transport and removal from urban street canyons.

Wind flows in urban areas are complicated. The drag induced by urban surfaces increases the aerodynamic resistance (Raupach et al. 1991; MacDonald et al. 1998), and modifies the dynamics inside and over street canyons. For chemically reactive pollutant, the transport process is partitioned into advection, diffusion, and chemistry components. Advection of pollutants is mainly controlled by mean flows. Higher wind speeds are thus beneficial to pollutant removal over urban areas. Pollutant diffusion is the pollutant transport due to random motions that is largely affected by turbulence structure. Diffusion is important to the pollutant removal from pedestrian level to the $\mathrm{ABL}$ aloft. Chemical reactions result in the dilution of reactants and production of secondary pollutants which are functions of pollutant concentrations, temperature, and chemical kinetics. 
Computational fluid dynamics (CFD) is widely adopted to tackle air pollution physics-chemistry coupling nowadays. In general, numerical methods for CFD are grouped into three categories, namely the direct numerical simulation (DNS), Reynolds-averaged Navier-Stokes (RANS) equations, and large-eddy simulation (LES). CFD models are well received in industry and academic research because of their availability of high-resolution results in spatio-temporal domain. Most CFD studies have focused on the reactive pollutant transport inside a street canyon (Baik et al. 2007; Chung and Liu 2012). However, the pollutant transport over street canyons is not fully understood. The correlation among advection, diffusion, and chemistry is not clear yet. To fully elucidate the pollutant transport mechanism in urban areas, it is necessary to look into the contributions of advection, diffusion, and chemistry in pollutant transport processes.

This paper looks into the transport mechanism of chemically reactive pollutants over idealised urban roughness using LES. The contributions of advection, diffusion, and chemistry to the transport equation are investigated. This section introduces the problem background and reviews the available literature. Afterwards, the theory of pollutant transport and budget equations is derived. Next, the methodology of LES and the computational domain are detailed. The findings of the pollutant transport processes are reported before the conclusions are drawn.

\section{Theoretical background}

In this section, the dimensionless ensemble-average transport equation for $2 \mathrm{D}$ flows of chemically reactive pollutants is derived based on the advection-diffusion equation with chemistry source/sink:

$$
\frac{\partial \phi}{\partial t}+u_{i} \frac{\partial \phi}{\partial x_{i}}=K \frac{\partial^{2} \phi}{\partial x_{i}^{2}}+S_{\phi}
$$

where $\phi$ is the concentration of chemical species, $u_{i}$ the wind speed, $x_{i}$ the Cartesian coordinate, $K$ the mass diffusivity, and $S_{\phi}$ the source term handling pollution chemistry. For simple dilution in turbulent flows, molecular diffusion can be neglected in the Eulerian framework. Hence, Eq. (1) is simplified to

$$
\frac{\partial \phi}{\partial t}+u_{i} \frac{\partial \phi}{\partial x_{i}}=S_{\phi}
$$

The irreversible ozone $\left(\mathrm{O}_{3}\right)$ titration oxidizes nitric oxide (NO) to nitrogen dioxide $\left(\mathrm{NO}_{2}\right)$, representing the typical anthropogenic pollution chemistry:

$$
\mathrm{NO}+\mathrm{O}_{3} \stackrel{k_{3}}{\longrightarrow} \mathrm{NO}_{2}+\mathrm{O}_{2} .
$$

Based on Eq. (3), the source terms for $\mathrm{NO}, \mathrm{O}_{3}$, and $\mathrm{NO}_{2}$ are

$$
\begin{aligned}
& \frac{\mathrm{d}[\mathrm{NO}]}{\mathrm{d} t}=-k_{3}\left[\mathrm{O}_{3}\right][\mathrm{NO}], \\
& \frac{\mathrm{d}\left[\mathrm{O}_{3}\right]}{\mathrm{d} t}=-k_{3}\left[\mathrm{O}_{3}\right][\mathrm{NO}]
\end{aligned}
$$

and

$$
\frac{\mathrm{d}\left[\mathrm{NO}_{2}\right]}{\mathrm{d} t}=k_{3}\left[\mathrm{O}_{3}\right][\mathrm{NO}]
$$

respectively. Taking NO as an example for demonstration, its transport is given by

$$
\frac{\partial \phi_{\mathrm{NO}}}{\partial t}+u_{i} \frac{\partial \phi_{\mathrm{NO}}}{\partial x_{i}}=S_{\phi_{\mathrm{NO}}} .
$$

Considering the definition of advection timescale

$$
T_{0}=L_{0} / U_{0},
$$

chemistry timescale

$$
\tau_{\mathrm{NO}}^{-1}=\frac{\partial[\mathrm{NO}]}{\partial t} \times \frac{1}{[\mathrm{NO}]}=\frac{\partial[\mathrm{NO}]}{\partial t} \times \frac{1}{\left[\mathrm{NO}_{0}\right.}=-k_{3}\left[\mathrm{O}_{3}\right]_{0},
$$

and the Damköhler number $\mathrm{Da}=T_{0} / \tau_{\mathrm{NO}}$ (relative time between physics and chemistry), the dimensionless transport equation for $\mathrm{NO}$ can be finally derived as

$$
\frac{\partial \hat{\phi}_{\mathrm{NO}}}{\partial \hat{t}}+\hat{u}_{i} \frac{\partial \hat{\phi}_{\mathrm{NO}}}{\partial \hat{x}_{i}}=-\mathrm{Da}_{\mathrm{NO}} \hat{\phi}_{\mathrm{NO}} \hat{\phi}_{\mathrm{O}_{3}},
$$

where $L_{0}$ is the length scale and $U_{0}$ the velocity scale.

Take the ensemble average as follows:

$$
\psi=\langle\psi\rangle+\psi^{\prime \prime},
$$

where $\psi$ represents the resolved scale, $\langle\psi\rangle$ the ensemble average (in time and spanwise domain), and $\psi^{\prime \prime}$ the fluctuating component. Hence

$$
\begin{aligned}
\psi \cdot \psi & =\left(\langle\psi\rangle+\psi^{\prime \prime}\right) \times\left(\langle\psi\rangle+\psi^{\prime \prime}\right) \\
& =\langle\psi\rangle \cdot\langle\psi\rangle+\langle\psi\rangle \cdot \psi^{\prime \prime}+\langle\psi\rangle \cdot \psi^{\prime \prime}+\psi^{\prime \prime} \cdot \psi^{\prime \prime} .
\end{aligned}
$$

The ensemble average of $\psi \cdot \psi$ is thus

$$
\langle\psi \cdot \psi\rangle=\langle\psi\rangle\langle\psi\rangle+\left\langle\psi^{\prime \prime} \psi^{\prime \prime}\right\rangle,
$$


where $\langle\psi\rangle\langle\psi\rangle$ is the mean component and $\left\langle\psi^{\prime \prime} \psi^{\prime \prime}\right\rangle$ is the fluctuation component.

Taking the ensemble average of the dimensionless transport Eq. (10) yields

$$
\begin{gathered}
\left\langle\frac{\partial \hat{\phi}_{\mathrm{NO}}}{\partial \hat{t}}\right\rangle+\left\langle\hat{u}_{i} \frac{\partial \hat{\phi}_{\mathrm{NO}}}{\partial \hat{x}_{i}}\right\rangle=-\operatorname{Da}_{\mathrm{NO}}\left\langle\hat{\phi}_{\mathrm{NO}} \hat{\phi}_{\mathrm{O}_{3}}\right\rangle, \\
\left\langle\frac{\partial \hat{\phi}_{\mathrm{NO}}}{\partial \hat{t}}\right\rangle+\left\langle\hat{u}_{i}\right\rangle \frac{\partial\left\langle\hat{\phi}_{\mathrm{NO}}\right\rangle}{\partial \hat{x}_{i}}+\frac{\partial}{\partial \hat{x}_{i}}\left\langle\hat{u}_{i}^{\prime \prime} \hat{\phi}_{\mathrm{NO}}^{\prime \prime}\right\rangle \\
=-\mathrm{Da}_{\mathrm{NO}}\left(\left\langle\hat{\phi}_{\mathrm{NO}}\right\rangle\left\langle\hat{\phi}_{\mathrm{O}_{3}}\right\rangle+\left\langle\hat{\phi}_{\mathrm{NO}}^{\prime \prime} \hat{\phi}_{\mathrm{O}_{3}}^{\prime \prime}\right\rangle\right),
\end{gathered}
$$

and

$$
\begin{gathered}
\left\langle\frac{\partial \hat{\phi}_{\mathrm{NO}}}{\partial \hat{t}}\right\rangle=-\left\langle\hat{u}_{i}\right\rangle \frac{\partial\left\langle\hat{\phi}_{\mathrm{NO}}\right\rangle}{\partial \hat{x}_{i}}-\frac{\partial}{\partial \hat{x}_{i}}\left\langle\hat{u}_{i}^{\prime \prime} \hat{\phi}_{\mathrm{NO}}^{\prime \prime}\right\rangle \\
-\mathrm{Da}_{\mathrm{NO}}\left(\left\langle\hat{\phi}_{\mathrm{NO}}\right\rangle\left\langle\hat{\phi}_{\mathrm{O}_{3}}\right\rangle+\left\langle\hat{\phi}_{\mathrm{NO}}^{\prime \prime} \hat{\phi}_{\mathrm{O}_{3}}^{\prime \prime}\right\rangle\right) .
\end{gathered}
$$

Pseudo steady-state condition $\left\langle\partial \hat{\phi}_{\mathrm{NO}} / \partial \hat{t}\right\rangle=0$ is applied, so Eq. (16) is simplified to

$$
\begin{aligned}
& -\left\langle\hat{u}_{i}\right\rangle \frac{\partial\left\langle\hat{\phi}_{\mathrm{NO}}\right\rangle}{\partial \hat{x}_{i}}-\frac{\partial}{\partial \hat{x}_{i}}\left\langle\hat{u}_{i}^{\prime \prime} \hat{\phi}_{\mathrm{NO}}^{\prime \prime}\right\rangle \\
& -\operatorname{Da}_{\mathrm{NO}}\left(\left\langle\hat{\phi}_{\mathrm{NO}}\right\rangle\left\langle\hat{\phi}_{\mathrm{O}_{3}}\right\rangle+\left\langle\hat{\phi}_{\mathrm{NO}}^{\prime \prime} \hat{\phi}_{\mathrm{O}_{3}}^{\prime \prime}\right\rangle\right)=0 .
\end{aligned}
$$

For 2D flows over street canyon, the budget equation for transport of chemically reactive pollutant is

$$
\begin{aligned}
& -\langle\hat{u}\rangle \frac{\partial\left\langle\hat{\phi}_{\mathrm{NO}}\right\rangle}{\partial \hat{x}}-\langle\hat{w}\rangle \frac{\partial\left\langle\hat{\phi}_{\mathrm{NO}}\right\rangle}{\partial \hat{z}}-\frac{\partial}{\partial \hat{x}}\left\langle\hat{u}^{\prime \prime} \hat{\phi}_{\mathrm{NO}}^{\prime \prime}\right\rangle \\
& -\frac{\partial}{\partial \hat{z}}\left\langle\hat{w}^{\prime \prime} \hat{\phi}_{\mathrm{NO}}^{\prime \prime}\right\rangle-\mathrm{Da}_{\mathrm{NO}}\left\langle\hat{\phi}_{\mathrm{NO}}\right\rangle\left\langle\hat{\phi}_{\mathrm{O}_{3}}\right\rangle-\mathrm{Da}_{\mathrm{NO}}\left\langle\hat{\phi}_{\mathrm{NO}}^{\prime \prime} \hat{\phi}_{3}^{\prime \prime}\right\rangle=0 .
\end{aligned}
$$

The first two terms are the streamwise advection $\left(A \_x\right)$ and vertical advection $\left(A_{-} z\right)$, the third term streamwise turbulent diffusion term $\left(D \_x\right)$, the fourth term the vertical turbulent diffusion $\left(D \_z\right)$, the fifth term the chemistry term based on mean pollutant concentrations $\left(C \_m\right)$, and the last term the correlation between pollutant fluctuations $\left(C_{-} f\right)$.

\section{Methods}

The computation in this paper is performed on the platform of OpenFOAM 2.3.0 (OpenFOAM 2015). LES is adopted to handle the turbulent flows and pollutant transport. The flows are assumed to be isothermal and incompressible which are calculated by the (filtered) continuity:

$$
\frac{\partial \bar{u}_{i}}{\partial x_{i}}=0
$$

and Navier-Stokes equations

$$
\frac{\partial \bar{u}_{i}}{\partial t}+\frac{\partial}{\partial x_{j}} \bar{u}_{i} \bar{u}_{j}=-\Delta P_{x} \delta_{i x}-\frac{\partial \bar{\pi}}{\partial x_{i}}-\frac{\partial \tau_{i j}}{\partial x_{j}}+v \frac{\partial^{2} \bar{u}_{i}}{\partial x_{j} \partial x_{j}},
$$

where $\bar{u}_{i}$ is the resolved-scale velocity component in the $i$-direction, $x_{i}$ the Cartesian coordinate, $\Delta P_{x}$ the background pressure gradient driving the prevailing flows in the (streamwise) $x$-direction, $v$ the kinematic viscosity, and $\delta_{i j}$ the Kronecker delta. The summation convention on repeated indices $(i, j=1,2$, and 3$)$ is applied. Overbar here represents the resolved scale in LES. The modified resolved-scale pressure is defined as follows:

$$
\bar{\pi}=\bar{p}+\frac{2}{3} k_{\mathrm{SGS}},
$$

where $\bar{p}$ is the resolved-scale kinematic pressure and $k_{\mathrm{SGS}}\left(=\tau_{i i} / 2\right)$ is the subgrid-scale (SGS) turbulence kinetic energy (TKE). The SGS momentum flux $\tau_{i j}\left(=\overline{u_{i} u_{j}}-\bar{u}_{i} \bar{u}_{j}\right)$ is modelled in the form:

$$
\tau_{i j}-\frac{2}{3} k_{\mathrm{SGS}} \delta_{i j}=-v_{\mathrm{SGS}}\left(\frac{\partial \bar{u}_{i}}{\partial x_{j}}+\frac{\partial \bar{u}_{j}}{\partial x_{i}}\right),
$$

using the Smagorinsky model (Smagorinsky 1963). Here, $v_{\mathrm{SGS}}\left(=C_{k} k_{\mathrm{SGS}}^{1 / 2} \Delta\right)$ is the kinematic eddy viscosity, $\Delta$ $\left(=[\Delta x \Delta y \Delta z]^{1 / 3}\right)$ the LES filter width, and $C_{k}(=0.07)$ an empirical modelling constant. The one-equation SGS model (Schumann 1975)

$$
\begin{aligned}
& \frac{\partial k_{\mathrm{SGS}}}{\partial t}+\frac{\partial}{\partial x_{i}} k_{\mathrm{SGS}} \bar{u}_{i} \\
& =\frac{1}{2} \tau_{i j} \frac{\partial \bar{u}_{i}}{\partial x_{j}}+\left(v+v_{\mathrm{SGS}}\right) \frac{\partial^{2} k_{\mathrm{SGS}}}{\partial x_{i} \partial x_{i}}-C_{\xi} \frac{k_{\mathrm{SGS}}^{3 / 2}}{\Delta}
\end{aligned}
$$

is employed to handle the SGS TKE conservation where $C_{\xi}(=1.05)$ is another empirical modelling constant. The (filtered) transport equation for a chemically reactive species $\phi$ is as follows:

$$
\frac{\partial \bar{c}_{\phi}}{\partial t}+\frac{\partial}{\partial x_{i}} \bar{c}_{\phi} \bar{u}_{i}=-\frac{\partial \gamma_{i}}{\partial x_{i}}+\frac{v}{\operatorname{Sc}} \frac{\partial^{2} \bar{c}_{\phi}}{\partial x_{i} \partial x_{i}}+\bar{S}_{\phi}
$$

where $\bar{c}_{\phi}$ is the resolved-scale concentration of chemical species $\phi$. Sc $(=0.72)$ is the Schmidt number and $\gamma_{i}$ $\left(=\overline{c_{\phi} u_{i}}-\bar{c}_{\phi} \bar{u}_{i}\right)$ is the SGS flux of reactive species which is modelled using the eddy-viscosity approach: 


$$
\gamma_{i}=\frac{\nu_{\mathrm{SGS}}}{\mathrm{Sc}} \frac{\partial \bar{c}_{\phi}}{\partial x_{i}}
$$

The last term on the right-hand side (RHS) of Eq. (24) $\bar{S}_{\phi}$ is the source term handling the irreversible ozone titration Eq. (3). It is assumed that the background oxygen $\left[\mathrm{O}_{2}\right]_{0}(\approx 20 \%$ by volume) is abundant whose change due to the ozone titration is negligibly small. We, therefore, only consider the resolved-scale gaseous chemistry among nitric oxide, nitrogen dioxide, and ozone in the source terms.

The LES model for hypothetical urban areas consists of a number of idealised urban street canyons modelled by identical square ribs of size $h$ (Fig. 1 ). The spatial domain sizes $72 h$ (length) $\times 12 h$ (width) $\times 12 h$ (height) that is composed of 36 idealised street canyons of the same geometry (Fig. 1). The street width $b$ and the building height $h$ are the same, so the building-heightto-street-width (aspect) ratio is equal to unity. The flows thus fall into the skimming flow regime. Details of the spatial discretization for all the configurations are listed in Table $1 . N_{x}$ is the grid number in streamwise direction above the roof level. $N_{y}$ is the grid number in spanwise direction. $N_{z}$ is the grid number in vertical direction in the ASL core above the roof level. $N_{x-\text { canyon }}$ and $N_{z \text {-canyon }}$ are the grid numbers in streamwise direction and vertical direction inside the street canyons, respectively. $N_{- \text {total }}$ is the total grid number in the whole computational domain. $\Delta x$ and $\Delta y$ are the grid sizes in streamwise and spanwise directions, respectively. $\Delta z_{-\min }$ and $\Delta z_{-\max }$ are, respectively, the minimum and maximum grid sizes in vertical direction. The Damköhler number in this case is 0.9445 , so the advection and chemistry timescales are comparable to each other.

The prevailing flows in the urban ABL are driven by the (background) pressure gradient $\Delta P_{x}$ perpendicular to the street axes, representing the worst scenario of pollutant removal from street canyons. The domain extent is $12 h$ in the homogeneous spanwise $y$-direction. The inlet and outlet boundaries for velocity are specified as cyclic

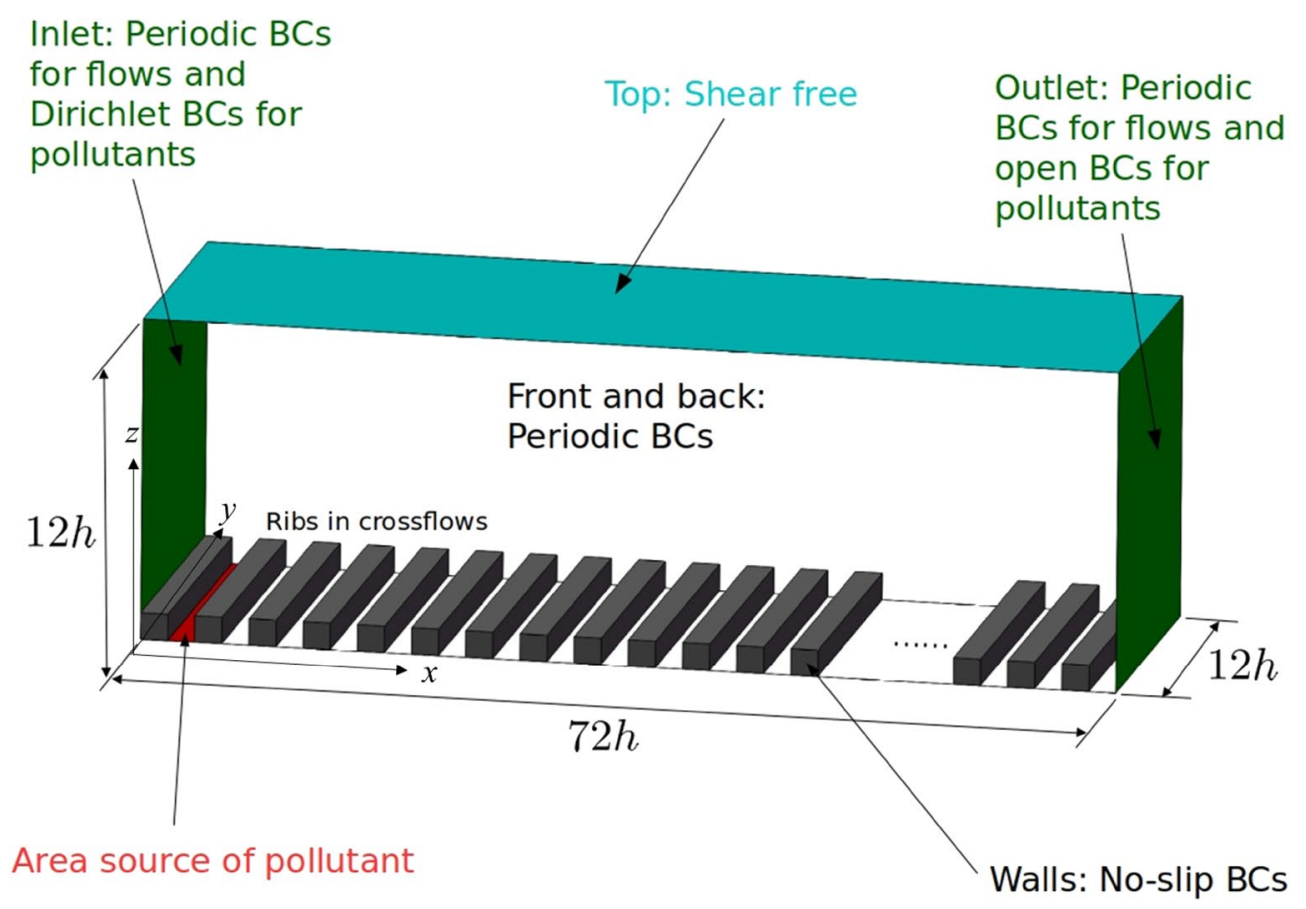

Fig. 1 LES computational domain

Table 1 Spatial discretization of the computational domain

\begin{tabular}{lllllll}
\hline Grid number & $N_{x}$ & $N_{y}$ & $N_{z}$ & $N_{x-\text { canyon }}$ & $N_{z-\text { canyon }}$ & 12 \\
Mesh size & 864 & 96 & 73 & 12 & $N_{- \text {total }}$ & $6,552,576$ \\
& $\Delta x$ & $\Delta y$ & $\Delta z_{-\max }$ & 0.2515 & \\
\hline
\end{tabular}


boundary conditions (BCs) to simulate an infinitely long streamwise $x$ domain. The domain outflow then goes back to the inlet. Cyclic BCs are also applied in the horizontal directions to simulate wind flows and pollutant dispersion over an infinitely large urban area. Wall BCs are applied on all the solid boundaries and a shear-free $\mathrm{BC}$ along the domain top. The prevailing wind enters the spatial domain from the upstream inflow doped with constant background ozone concentrations $\left[\mathrm{O}_{3}\right]_{0}$ $(=100 \mathrm{ppb})$. Our preliminary LES results show that the ozone consumption $\Delta\left[\mathrm{O}_{3}\right]$ is less than $10 \%$. We, therefore, assume a constant chemistry timescale of nitric oxide $\tau_{\mathrm{NO}}=1 / k_{3}\left[\mathrm{O}_{3}\right]_{0}$ in the parameterization. A constant-concentration area source of nitric oxide $[\mathrm{NO}]_{0}(=1000 \mathrm{ppb})$ is placed on the ground surface of the first street canyon where a reactive pollutant is continuously emitted into the computational domain, simulating the dispersion of vehicular exhaust. Neumann BCs for scalars are applied on all the solid boundaries. An open BC of pollutants is prescribed at the downstream outflow, so all the chemical species are removed from the computational domain without any reflection.

\section{Results}

\section{Flow structure and validation}

Figure 2 depicts the flow properties in the urban ABL over the rib-type hypothetical urban surface described previously. The wall-normal distance $z$ is normalised by the ABL thickness $H$ and the velocity is normalised by the prevailing wind speed $U_{\infty}$. Similar to that of openchannel flows, the ensemble-averaged (time and spanwise averaged) streamwise velocity $\langle\bar{u}\rangle$ increases rapidly with increasing wall-normal distance over the roughness elements, converging gradually to the prevailing wind speed $U_{\infty}$ at the domain top. The mean-wind-speed profile (Fig. 2a) agrees well with that of our previous windtunnel measurements (Ho and Liu 2016). The streamwise $\left\langle u^{\prime \prime} u^{\prime \prime}\right\rangle^{1 / 2}$ (Fig. 2b) and the vertical $\left\langle w^{\prime \prime} w^{\prime \prime}\right\rangle^{1 / 2}$ (Fig. 2c) fluctuating velocities are normalised by the friction velocity $u_{*}\left(=\left(\tau_{w} / \rho\right)^{1 / 2}=0.0469\right.$, where $\tau_{w}$ and $\rho$ are the wall shear stress and the fluid density, respectively). Here, double prime $\phi^{\prime \prime}(=\bar{\phi}-\langle\bar{\phi}\rangle)$ denotes the fluctuating component of the resolved-scale variables. A good agreement of fluctuating velocities, especially in the lower urban $\mathrm{ABL}$, between the current LES and the previous windtunnel measurements is observed. As shown in Fig. 2d, the current LES results and the previous wind-tunnel measurements (Ho and Liu 2016) consistently exhibit the conventional characteristics of ensemble-averaged vertical momentum flux $\left\langle u^{\prime \prime} w^{\prime \prime}\right\rangle$ that decreases with increasing wall-normal distance. Negative momentum flux signifies the momentum entrainment from the core flows down to the near-wall region that is a major energy source for

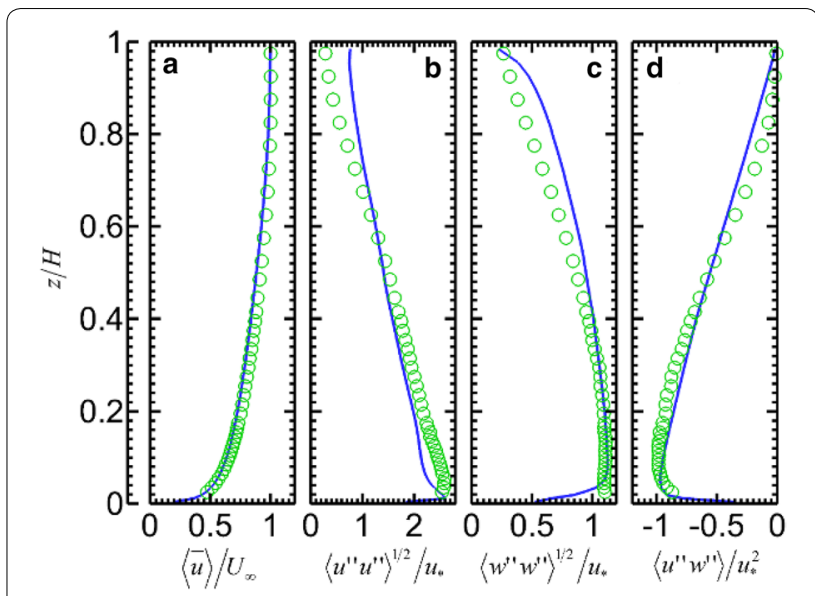

Fig. 2 Vertical profiles of $\mathbf{a}$ mean wind speed; $\mathbf{b}$ streamwise fluctuating velocity; $\mathbf{c}$ vertical fluctuating velocity; $\mathbf{d}$ vertical momentum flux. Solid line: LES data; symbols: wind-tunnel data (Ho and Liu 2016)

street-level pollutant removal. The vertical momentum flux $\left\langle u^{\prime \prime} w^{\prime \prime}\right\rangle$ in the wind-tunnel measurements deviates slightly from linearity because of the higher background turbulence intensity $(\approx 10 \%)$ compared with that of the LES. On the other hand, the LES-calculated total momentum flux is almost linearly proportional to the wall-normal distance $z$ that agrees well with the theoretical solution.

\section{Budget analysis for inert pollutant transport}

Figure 3 depicts the budget analysis for inert pollutant and the vertical profiles of dimensionless concentration $\left\langle\hat{c}_{\phi}\right\rangle$ in different streamwise location $x$. The wall-normal distance $z$ is normalised by the vertical pollutant dispersion coefficient $\sigma_{z}$. LES output shows that the vertical advection term is negligible in the whole computational domain. A mild fluctuation of vertical advection is found only at the roof level mainly because of the elevated local shear stress. Near the pollutant source $(x / h=15.54)$, the streamwise diffusion $\left(D_{-} x\right)$ shifts from positive to negative in the region $z / \sigma_{z}<2.8$. In the far field $(x / h>35.54)$, the streamwise diffusion $\left(D \_x\right)$ fluctuates more frequently and an obvious abrupt change can be found at the roof level. The streamwise advection $\left(A \_x\right)$ shifts from negative to positive near the roof level. It switches back to negative again, which is counterbalanced by the vertical diffusion $\left(D \_z\right)$. Fluctuations of advection and diffusion terms are noticeable below the roof level in the street canyons. The reason behind is the recirculating flows inside the street canyons that complicate the pollutant transport there. The vertical profiles at $x / h=35.54$ and $x / h=65.54$ (Fig. $3 \mathrm{~b}$ and c) are not as smooth as those in the near field (Fig. 3a) mainly because of the decreasing 

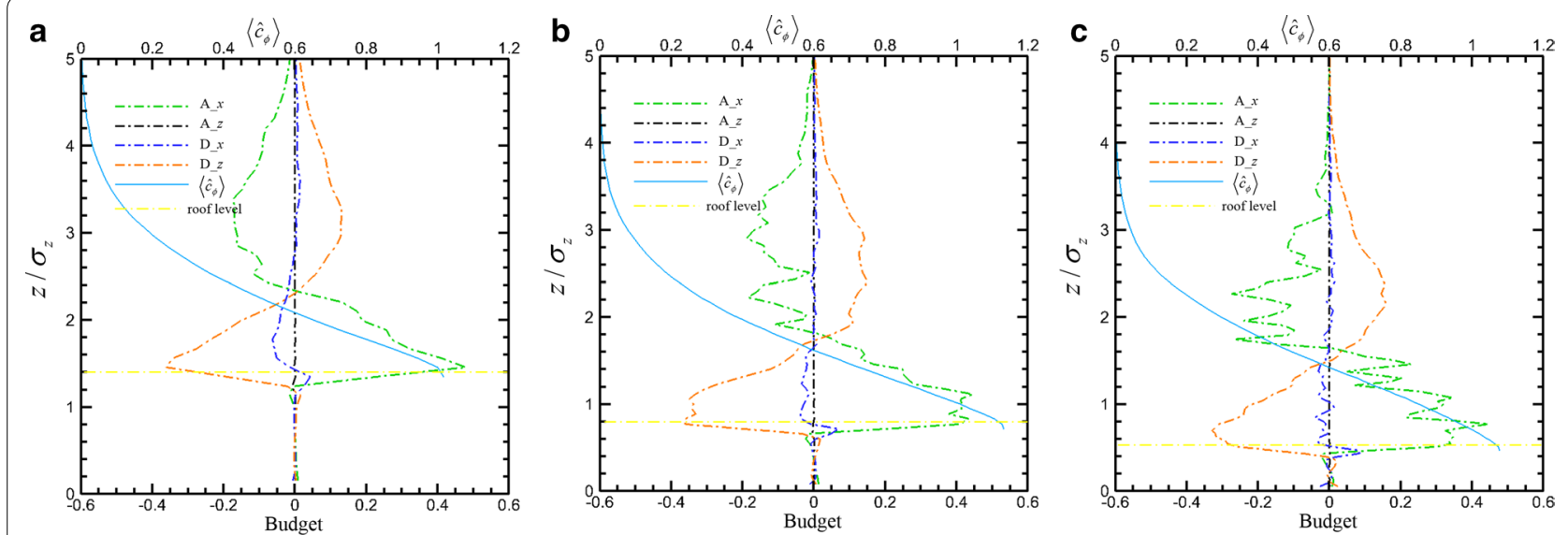

Fig. 3 Budget analysis and vertical profiles of passive scalar concentration in the streamwise direction at $\mathbf{a} x / h=15.54 ; \mathbf{b} \times / h=35.54 ; \mathbf{c} \times / h=65.54$

pollutant concentrations in the far field in the streamwise direction.

\section{Budget analysis for NO transport}

In the previous section, we analyze the budget for passive scalar. Streamwise advection and vertical diffusion counterbalance each other except at the roof level. For chemically reactive pollutants, in view of the fast chemical reaction in the $\mathrm{ABL}$, the transport behaviour of $\mathrm{NO}$ is different from that of inert scalar. The turbulence generated from mean flows and roughness elements affects the mixing of chemical species, further complicating the ABL pollutant dispersion. Figure 4 depicts the budget analysis for $\mathrm{NO}$ in different streamwise location. The vertical advection $\left(A \_z\right)$ and chemistry fluctuation correlation $\left(C \_f\right)$ are not shown in the figure, because they are negligible compared with other terms. Similar to that of inert scalar, the streamwise diffusion of reactive pollutants is also small except at the roof level. A sharp decrease in roof-level streamwise diffusion is attributed to the shear layer there. In the field near the pollutant source $(x / h=15.54)$, the streamwise advection is counterbalanced by both chemistry and vertical diffusion terms, which reach their peaked values at plume centre (the location of the peaked pollutant concentration; $z$ / $\left.\sigma_{z}=1.6\right)$. The NO plume is not fully developed in the near field; the chemistry term is important but not dominant. At the roof level, the vertical diffusion of passive scalar is negative. However, the vertical diffusion of NO is positive to provide more reactants for chemical reaction and streamwise advection. In view of the enhanced mixing of chemical species, the chemistry term is significant that is counterbalanced by the streamwise advection.

\section{Conclusions}

LES is conducted to examine the pollutant dispersion over hypothetical urban areas in the form of identical ribs in crossflows. Budget analysis is applied to elucidate the significance of advection, diffusion, and chemistry in the pollutant transport process. LES output shows that
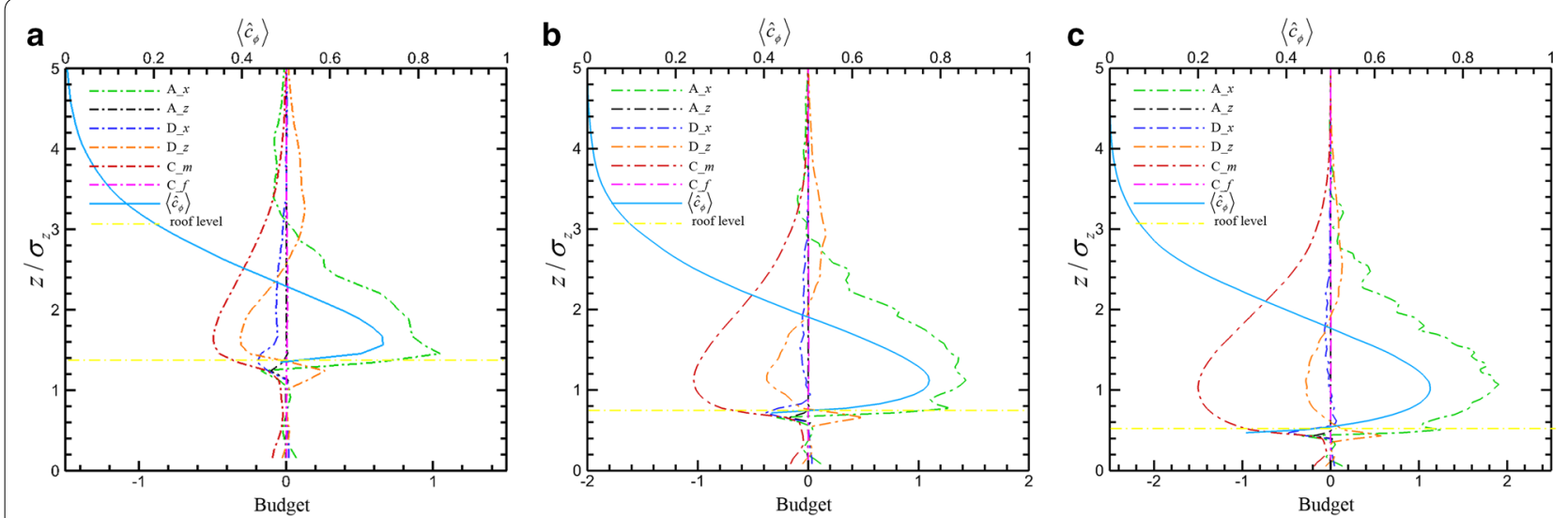

Fig. 4 Budget analysis and vertical profiles of NO concentration in the streamwise direction at $\mathbf{a} x / h=15.54 ; \mathbf{b} \times / h=35.54 ; \mathbf{c} \times / h=65.54$ 
the three terms are coupled and counterbalanced with each other. Streamwise diffusion is only notable at the roof level. The chemistry term is affected by the mixing of pollutant species. In the near fields, streamwise advection is counterbalanced by vertical diffusion and chemistry. In the far field, pollution chemistry becomes more important when the NO plume is fully developed, and the mixing of $\mathrm{NO}$ and $\mathrm{O}_{3}$ is more sufficient. Comparing to pollutant dimensionless vertical profiles, it is also found that different terms arrive their peaked values at the plume centre.

\section{Authors' contributions}

The authors contributed equally to this paper. All authors read and approved the final manuscript.

\section{Acknowledgements}

The first author wishes to thank the Hong Kong Research Grants Council (RGC) for financially supporting his study through the Hong Kong Ph.D. fellowship (HKPF) scheme. This research is conducted in part using the research computing facilities and/or advisory services offered by Information Technology Services (ITS), The University of Hong Kong (HKU). Technical support from Ms. Lilian Y. L. Chan, Mr. W. K. Kwan, and Mr. Bill H. T. Yau is appreciated. This project is partly supported by the General Research Fund (GRF) of RGC HKU 17210115

\section{Competing interests}

The authors declare that they have no competing interests.

\section{Availability of data and materials}

Not applicable.

\section{Consent for publication}

Not applicable.

Ethics approval and consent to participate

Not applicable.
Funding

Hong Kong Ph.D. fellowship (HKPF) scheme and General Research Fund (GRF) 17210115 of HK Research Grant Council (RGC).

\section{Publisher's Note}

Springer Nature remains neutral with regard to jurisdictional claims in published maps and institutional affiliations.

Received: 27 February 2018 Accepted: 28 July 2018

Published online: 09 August 2018

\section{References}

Baik J-J, Kang Y-S, Kim J-J (2007) Modeling reactive pollutant dispersion in an urban street canyon. Atmos Environ 41(5):934-949

Chung TNH, Liu C (2012) Large-eddy simulation of reactive pollutant dispersion for the spatial instability of photostationary state over idealised 2D urban street canyons. Int J Environ Pollut 50:2-6

EPD (The Environmental Protection Department) (2016) Hong Kong air pollutant emission inventory. https://epd.gov.hk/epd/english/environmentinhk /air/data/emission inve.html\#El report. Accessed 23 June 2018

Ho Y-K, Liu C-H (2016) A wind tunnel study of flows over idealised urban surfaces with roughness sublayer corrections. Theor Appl Climatol. https //doi.org/10.1007/s00704-016-1877-8

MacDonald RW, Griffiths RF, Hall DJ (1998) A comparison of results from scaled field and wind tunnel modelling of dispersion in arrays of obstacles. Atmos Environ 32(3845-530):3862

OpenFOAM (2015) OpenFOAM: the open source CFD toolbox. http://www. openfoam.com/. Accessed 23 June 2018

Raupach MR, Antonia RA, Rajagopalan S (1991) Rough-wall turbulent boundary layers. Appl Mech Rev 44:1-25

Schumann U (1975) Subgrid scale model for finite difference simulations of turbulent flows in plane channels and annuli. J Comp Phys 18:376-404

Smagorinsky J (1963) General circulation experiments with the primative equations I: the basic experiment. Month Weath Rev 91:99-165

\section{Submit your manuscript to a SpringerOpen ${ }^{\odot}$ journal and benefit from:}

- Convenient online submission

- Rigorous peer review

- Open access: articles freely available online

- High visibility within the field

Retaining the copyright to your article 